\title{
Green Tea Extract-based Antioxidant Supplement
}

National Cancer Institute

\section{Source}

National Cancer Institute. Green Tea Extract-based Antioxidant Supplement. NCI

Thesaurus. Code C97514.

A dietary supplement containing a green tea extract including the catechin

epigallocatechin gallate and other vitamins and antioxidants, with potential antineoplastic

and chemopreventive activities. The polyphenols in green tea act as antioxidants and scavenge free radicals which may inhibit cellular oxidation and prevent free radical damage to cells. In addition, polyphenols may affect enzymes involved in cellular reproduction and tumor angiogenesis by modulating angiog enic factors. Other ing redients in green tea extract-based antioxidant supplement include dry cinnamon extract, germanium, zinc sulfate, manganese sulfate, arg inine, cysteine, malic acid, ascorbic acid (vitamin c), glycyrrhizinic acid, glycine, glucosamine, pyridoxal (vitamin B6), calcium pantothenate (vitamin B5), folic acid, cyanocobalamin (vitamin B12). 